\title{
Reducing health care-associated infections by implementing a novel all hands on deck approach for hand hygiene compliance
}

\author{
Emily E. Sickbert-Bennett PhD ${ }^{\mathrm{a}, \mathrm{b}, *}$, Lauren M. DiBiase MS $\mathrm{a}, \mathrm{b}$, Tina M. Schade Willis MD ${ }^{\mathrm{c}}$, \\ Eric S. Wolak MSN, MHA, RN, NE-BC ${ }^{\mathrm{d}}$, David J. Weber MD, MPH ${ }^{\mathrm{a}, \mathrm{b}}$, \\ William A. Rutala PhD, MPH a,b \\ a Hospital Epidemiology, University of North Carolina Health Care, Chapel Hill, NC \\ ${ }^{\mathrm{b}}$ Division of Infectious Diseases, University of North Carolina School of Medicine, Chapel Hill, NC \\ ${ }^{c}$ Division of Pediatric Critical Care Medicine, University of North Carolina School of Medicine, Chapel Hill, NC \\ ${ }^{\mathrm{d}}$ Division of Nursing, University of North Carolina Health Care, Chapel Hill, NC
}

Key Words:

Hand hygiene

health care-associated infections

Clostridium difficile

intervention

\begin{abstract}
Hand hygiene is a key intervention for preventing health care-associated infections; however, maintaining high compliance is a challenge, and accurate measurement of compliance can be difficult. A novel program that engaged all health care personnel to measure compliance and provide real-time interventions overcame many barriers for compliance measurement and proved effective for sustaining high compliance and reducing health care-associated infections.
\end{abstract}

Each year in the United States, an estimated 1.7 million cases of health care-associated infection occur, with 98,000 resulting in deaths and cost estimates of $>\$ 10$ billion. Although the fraction of health care-associated infections that are preventable with improvements in hand hygiene compliance is not known, 38\% of infections are estimated to occur because of cross-transmission. Hand hygiene is a key intervention in interrupting transmission between patients, health care personnel, and contaminated fomites in the environment. In fact, the association between improved hand hygiene compliance from low to higher rates and reductions in health careassociated infection rates has been well described. ${ }^{1,2}$ However, in 2002 when the Centers for Disease Control and Prevention Hand Hygiene guidelines were published, the overall hand hygiene compliance among the 34 published studies varied from $5 \%-81 \%$, with an average compliance of only $40 \%{ }^{1}$

Achieving high hand hygiene compliance remains a challenge, particularly in a health care setting where as many as 15.2 hand hygiene opportunities have been estimated to occur each hour. ${ }^{3}$ In addition, measuring hand hygiene compliance presents additional

\footnotetext{
* Address correspondence to Emily E. Sickbert-Bennett, PhD, Hospital Epidemiology, UNC Health Care, 1001 West Wing, CB\#7600, 101 Manning Dr, Chapel Hill, NC 27514 E-mail address: esickber@unch.unc.edu (E.E. Sickbert-Bennett).

Publication of this article was supported by an educational grant from Clorox Healthcare, Sealed Air, and Tru-D. Content of this article was initiated and written by the authors with no input or financial support to the authors from Clorox Healthcare, Sealed Air, or Tru-D.

Conflicts of interest: None to report.
}

challenges, including several potential sources of bias. Three types of bias are possible with hand hygiene compliance: interobserver variation, sampling bias, and the Hawthorne effect. With interobserver variation, hand hygiene observers may disagree on opportunities when hand hygiene should occur. Our hospital epidemiology department developed 6 real-life patient care scenarios and then conducted a survey among all department staff to assess appropriateness of hand hygiene. Among 12 hospital epidemiology personnel with a combined 150.5 years of experience, only 3 of the scenarios had $>75 \%$ agreement that hand hygiene was indicated. When the same scenarios were presented to a widely recognized expert on hand hygiene, for only 1 of those 3 scenarios did he share agreement that there was a clear indication for hand hygiene. Sampling bias may occur when the locations or time (time of day or day of week) for hand hygiene observations are not selected at random or the units sampled do not represent compliance for the entire facility. ${ }^{4}$ Finally, the Hawthorne effect is believed to heavily influence hand hygiene compliance measurements because individuals behave differently when they know they are being observed. Chen et al have proposed some solutions to combat the Hawthorne effect's potential for overestimates of hand hygiene compliance by, for example, only conducting 10 observations or for a 10 -minute time period in an area before changing locations. ${ }^{5}$ In addition, there are new technologies for hand hygiene measurements that electronically track health care personnel movement and interactions with soap or sanitizer dispensers which purport to alleviate these biases in providing objective and more complete hand hygiene observations. ${ }^{4,6}$ 


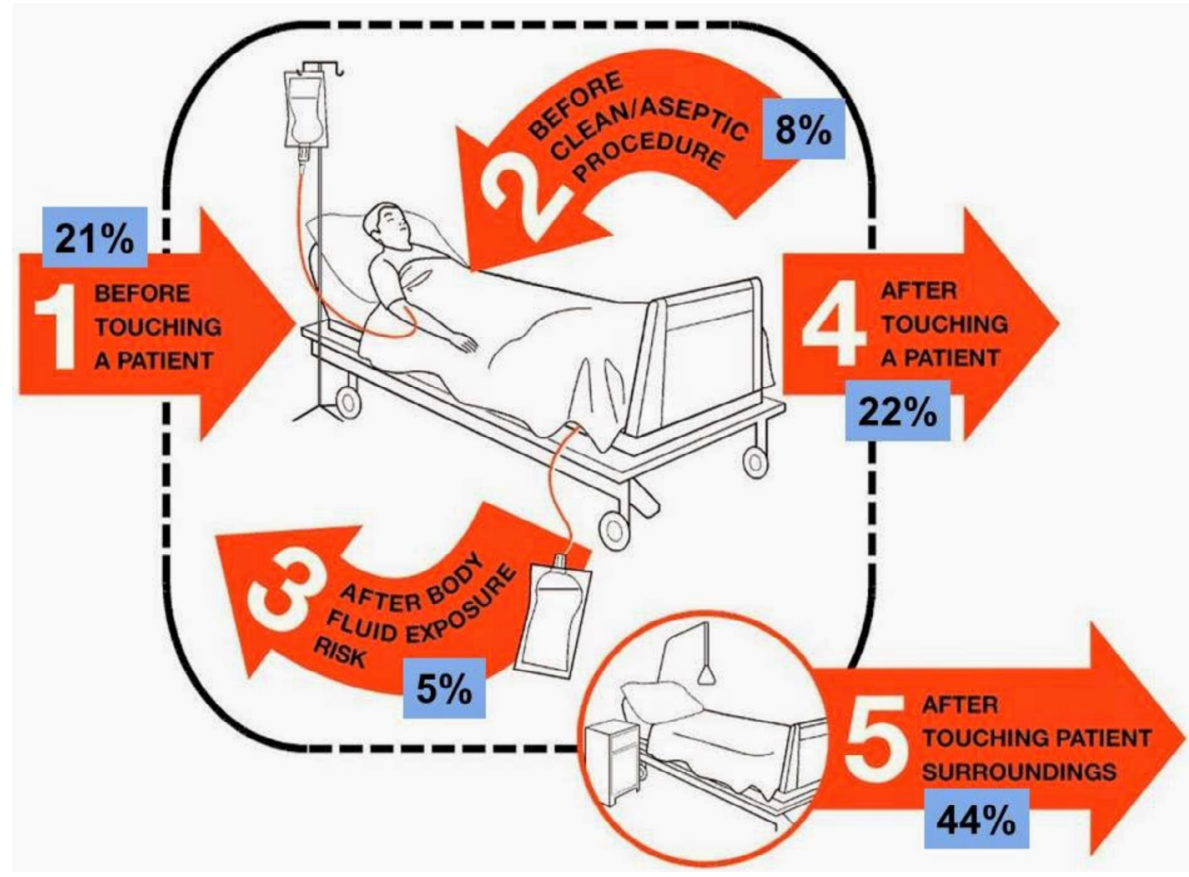

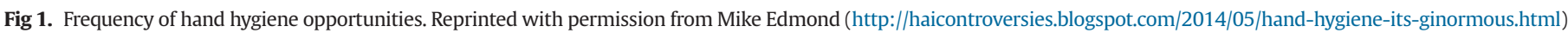
Data from Diller et al AJIC 2014 June.

Hand hygiene compliance at an $>800$-bed academic hospital was historically measured between $80 \%$ and $90 \%$ by infection prevention staff and designated infection control liaisons throughout the hospital. These measurements were subjected to the biases previously stated. Despite a requirement by the Joint Commission to show improvement, compliance remained relatively stable over several years. For these reasons, we developed a new program for hand hygiene compliance that engaged all frontline personnel in the effort. The program was adapted from a successful pilot program conducted in a pediatric intensive care unit where frontline health care personnel were involved in conducting hand hygiene compliance measurements among themselves. The engagement of health care personnel in monitoring and improving hand hygiene compliance and in other key infection prevention efforts led to demonstrated effectiveness in reducing health care-associated infections, patient length of stay, hospitalization costs, and mortality rates.

\section{METHODS}

To develop our all hands on deck approach for hand hygiene compliance, we first simplified the message for when to perform hand hygiene to "clean in, clean out." This message reminded all health care personnel (clinical and nonclinical) that each time they enter and exit a patient's room or space they need to perform hand hygiene with either an alcohol-based handrub, or antimicrobial soap and water. This expectation for hand hygiene was without exception, even housekeepers moving from room to room to pick up trash were required to perform hand hygiene in between each room. Although these 2 opportunities (ie, patient room entry, patient room exit) do not capture all of the World Health Organization's (WHO's) My 5 Moments for Hand Hygiene, they do represent most (87\%) of the situations (before touching a patient, after touching a patient, after touching patient surroundings) when hand hygiene is indicated based on video monitoring studies of the frequency of occurrence of each of the WHO's My 5 Moments for Hand Hygiene (Fig 1). ${ }^{8}$ Further, these 2 moments represent the most critical moments for interrupting patient-to-patient transmission of pathogens via the contaminated hands of health care personnel.
1. What date were the observations done?<smiles>C1=CC=C1</smiles>
$\mathrm{mm} / \mathrm{dd} / \mathrm{rm}$

2. Name of person doing the observations.

3. What is job classification of person deing the observations? Nursing Staff

Physidian/Advanced Practice Provider

Radiology Technologist

Occupational/Physical Therapist

Respiratory Therapist

Environmental Services/Housekeeping

Nutrition and Food Services/Dietary

Patient Transporters

Phlebotomy

Other

4. What location are these observations for?.

Plasu Solvect- *

5. Please complete the below table about the person being observed:

\begin{tabular}{|c|c|c|c|}
\hline & $\begin{array}{l}\text { Job Classification of Person } \\
\text { Observing }\end{array}$ & & Mand Hygiene \\
\hline Observation 1 & -Plesse Select- & $*$ & Please Select- . \\
\hline Observation 2 & Dresse Seloct- & $*$ & -Plesse Select- . \\
\hline Observation 3 & -Please Select- & $*$ & -Please Select- - \\
\hline Observation 4 & -Pease Select- & * & -Pease Select- . \\
\hline Observation 5 & -Please Select- & * & -Plesse Select- . \\
\hline Observation 6 & -Pease Select- & $*$ & -Plesse Select- - \\
\hline Observation 7 & -Pesse Select- & $*$ & -Plesse Select- - \\
\hline Observation 8 & - Prease Select- & $*$ & -Plesse Select- . \\
\hline Observation 9 & Dhease Select- & • & -Please Select- - \\
\hline Observation 10 & -Pease Select- & * & -Please Select- . \\
\hline
\end{tabular}

Fig 2. Survey tool for hand hygiene compliance observations. 
The simplification of the clean in, clean out program from the WHO's My 5 Moments for Hand Hygiene allowed for streamlined education to all personnel of the expectation for hand hygiene. In addition, all health care personnel (clinical and nonclinical) who entered patient rooms or spaces were asked to provide observations of other health care personnel's hand hygiene compliance. These observations were conducted in all inpatient settings and in many outpatient areas, procedural areas, and operating rooms. All health care personnel, including physicians, nurses, and members of housekeeping, radiology, phlebotomy, respiratory therapy, nutrition and food services, and occupational and physical therapy departments, who entered patient rooms were eligible to be observed and were asked to provide these observations. Two electronic methods were available for submitting observations: (1) iScrub app (compepi; The University of Iowa, Iowa City, IA) for Apple products and (2) a simple Internet-based survey tool (SelectSurvey.NETv4.146.008; University of North Carolina, Chapel Hill, NC) (Fig 2) accessible from the main page of the hospital's Intranet. Each department or location was asked to establish a bulletin board in a visible location to remind health care personnel of the methods to submit hand hygiene observations. Personnel also were able to track their progress on graph paper posted on the bulletin board in real time as they conducted observations.

\section{Example Run Chart:}

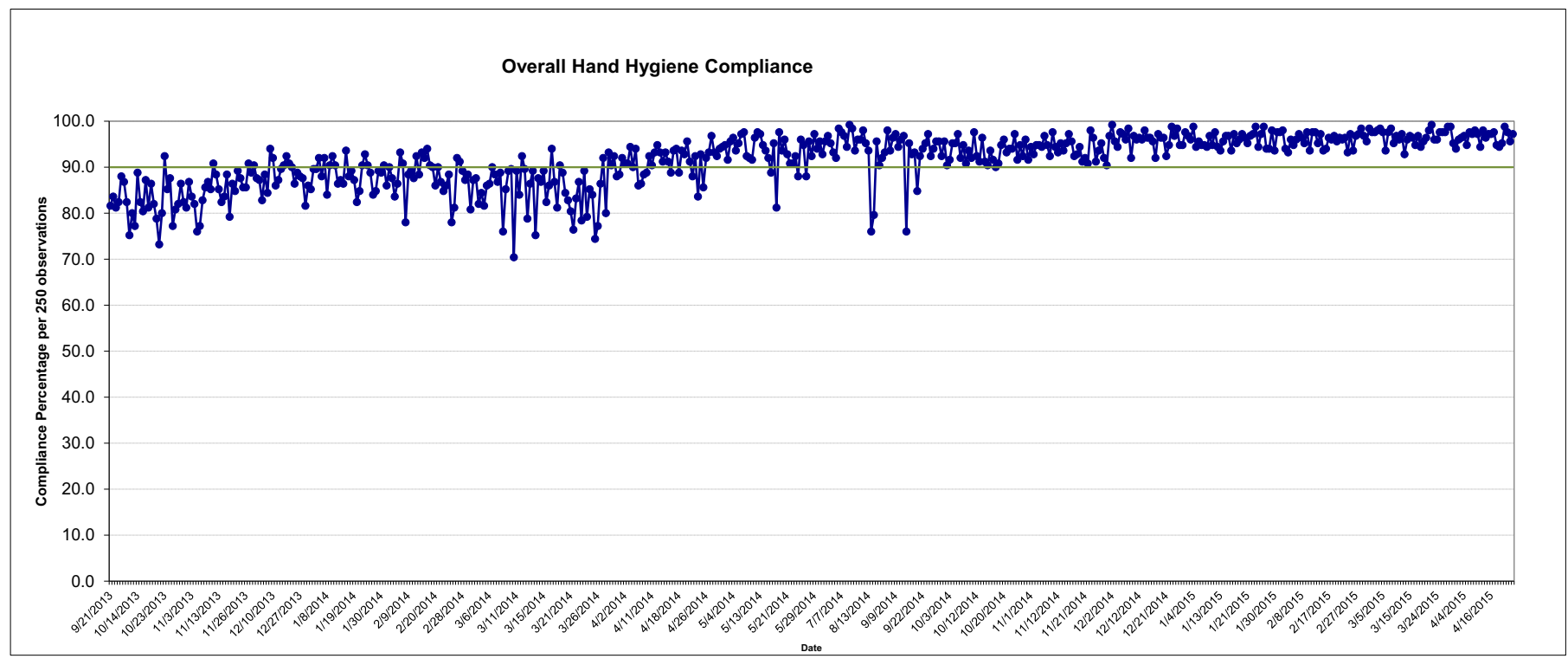

\section{Example Reports:}

Hand Hygiene Compliance Rate by Job Class

\begin{tabular}{|c|c|c|c|c|c|}
\hline \multicolumn{6}{|c|}{ GOAL: $90 \%$} \\
\hline & \multicolumn{5}{|c|}{ MARCH DATA } \\
\hline Job Classification & \begin{tabular}{|l|} 
Number of \\
Observations \\
Done By this \\
Job Class \\
\end{tabular} & $\begin{array}{l}\text { Number of } \\
\text { Unique } \\
\text { Observers }\end{array}$ & $\begin{array}{l}\text { Compliance } \\
\text { Rate }\end{array}$ & $\begin{array}{l}\text { Total Number } \\
\text { Observations } \\
\text { Done Of this Job } \\
\text { Class }\end{array}$ & $\begin{array}{l}\text { Percent of } \\
\text { Observations } \\
\text { Where } \\
\text { Feedback } \\
\text { Was Given by } \\
\text { This Job Class }\end{array}$ \\
\hline EVS/Housekeeping & 254 & 15 & 95.0 & 378 & P \\
\hline Imaging Specialist (Radiology) & 229 & 24 & 100.0 & 154 & 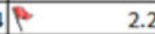 \\
\hline NFS/Dietary & 111 & 12 & 91.7 & 288 & 73.9 \\
\hline Nursing Staff & 6401 & 432 & 98.5 & 5120 & 58.2 \\
\hline Occupational/Physical Therapist & 221 & 37 & 98.8 & 244 & 16.3 \\
\hline Other & 452 & 28 & 92.3 & 491 & 20.1 \\
\hline Patient Transporter & 0 & & 84.1 & 164 & $\beta$ \\
\hline Phlebotomist & 1 & & 93.0 & 215 & 100.0 \\
\hline Physician/APp & 30 & & 95.1 & 1123 & 43.3 \\
\hline Respiratory Therapist & 950 & 34 & 97.2 & 465 & 45.9 \\
\hline Unknown & 0 & 0 & 85.7 & & $\beta$ \\
\hline
\end{tabular}

Fig 3. Example run chart and example reports. EVS, Environmental Services; NFS, Nutrition and Food Services; APP, Advanced Practice Provider. 
Personnel conducting observations were further asked to provide immediate feedback with their observations. Sample scripting and an illustrative video was produced to demonstrate how to remind noncompliant personnel to conduct hand hygiene when they forget or even believe that the activity they are performing does not require hand hygiene. Positive feedback on compliant hand hygiene opportunities was also highly encouraged. Nonpunitive, visible reminders were used, such as inviting personnel to wear a small hand sticker on their name badge. The hand sticker is a visible acknowledgement of commitment to clean in, clean out and signifies a health care personnel's willingness to receive a friendly reminder from a colleague when he or she forgets to perform hand hygiene.

Graphical and tabular reports detailing hand hygiene compliance for each area and job department were updated and disseminated to health care personnel each month. The number of unique observers, number of observations, and percentage of observations with feedback provided were also tracked by location and job department (Fig 3). Goals for the number of unique observers and percentage of observations with feedback were also established because these measures were important indicators of health care personnel participation and engagement. Comparative and detailed reports for each location's performance over time (ie, run charts) and compliance of different job classes within a location were provided for personnel to track progress and plan improvements. Each month the areas and departments were recognized with Golden Hand awards for improvement or exceptional participation, compliance, or feedback provided.

Periodically, areas and departments were asked to participate in focused action and sustainment planning. These action plans set specific goals and detailed new interventions to improve participation, compliance, and feedback. Suggested activities to improve compliance and participation included the following: focus on providing immediate feedback, after performing own observations ask another colleague to perform observations, and assigning embedded observers every shift.

\section{RESULTS}

Our analyses confirmed the importance of participation and engagement with improved compliance. The number of unique observers was a statistically significant predictor of hand hygiene within a job class $(P=.0096)$. Each additional 10 observers was associated with an increase of 0.1 percentage points of hand hygiene compliance within that job class. The percentage of feedback provided was also a statistically significant predictor of hand hygiene within a job class $(P=.0035)$. Each additional 10 percentage points of feedback was associated with an increase in hand hygiene compliance of 0.21 percentage points within that job class.

\section{CONCLUSIONS}

This novel approach using all health care personnel engaged in hand hygiene compliance improvement resolves several concerns with measurement bias. A simplified approach, such as the clean in, clean out program, limits the impact of interobserver variation because there are no exceptions to the simple expectation. By using all health care personnel throughout the hospital to provide observations of each other, no sampling for observations is necessary and the potential for sampling bias is greatly minimized. The impact of the Hawthorne effect is actually harnessed in this program because personnel are encouraged to provide ongoing feedback to one another while conducting observations. Although traditional hand hygiene compliance observations are designed to minimize the impact of the Hawthorne effect, the design of this approach is to capitalize on it as a real-time intervention to continuously improve hand hygiene compliance. Feedback that is timely, nonpunitive, individualized, and customizable is believed to be most effective at improving performance in individuals. ${ }^{9}$

To our knowledge, no published analysis, to date, has demonstrated whether an improvement in hand hygiene from a baseline high level (>80\%) to an even higher level (>95\%) has led to decreases in health care-associated infections. Over a 15 month period, we reduced our HAI rate by 0.9 infections per 1000 patient days and prevented 152 infections $(P=.0521){ }^{10}$

In conclusion, we have demonstrated that this novel strategy for hand hygiene compliance monitoring using frontline health care personnel who provide feedback is effective for sustaining high hand hygiene compliance. Importantly, we have also shown through this novel program that hand hygiene compliance improvements from already high rates can be an important strategy for achieving infection reductions.

\section{References}

1. Boyce JM, Pittet D, Healthcare Infection Control Practices Advisory Committee, HICPAC/SHEA/APIC/IDSA Hand Hygiene Task Force. Guideline for Hand Hygiene in Health-Care Settings. Recommendations of the Healthcare Infection Control Practices Advisory Committee and the HICPAC/SHEA/APIC/IDSA Hand Hygiene Task Force. Society for Healthcare Epidemiology of America/Association for Professionals in Infection Control/Infectious Diseases Society of America. MMWR Recomm Rep 2002;51:1-45.

2. Pittet D, Hugonnet S, Harbarth S, Mourouga P, Sauvan V, Touveneau S, et al. Effectiveness of a hospital-wide programme to improve compliance with hand hygiene. Infection Control Programme. Lancet 2000;356:1307-12.

3. World Health Organization. WHO guidelines on hand hygiene in health care: first global patient safety challenge clean care is safer care. Geneva, Switzerland: World Health Organization; 2009.

4. Jarrin Tejada C, Bearman G. Hand hygiene compliance monitoring: the state of the art. Curr Infect Dis Rep 2015;17:470.

5. Chen LF, Carriker C, Staheli R, Isaacs P, Elliott B, Miller BA, et al. Observing and improving hand hygiene compliance: implementation and refinement of an electronic-assisted direct-observer hand hygiene audit program. Infect Control Hosp Epidemiol 2013;34:207-10.

6. Boyce JM. Measuring healthcare worker hand hygiene activity: current practices and emerging technologies. Infect Control Hosp Epidemiol 2011;32:1016-28.

7. Harris BD, Hanson C, Christy C, Adams T, Banks A, Willis TS, et al. Strict hand hygiene and other practices shortened stays and cut costs and mortality in a pediatric intensive care unit. Health Aff (Millwood) 2011;30:1751-61.

8. Diller T, Kelly JW, Blackhurst D, Steed C, Boeker S, McElveen DC. Estimation of hand hygiene opportunities on an adult medical ward using 24-hour camera surveillance: validation of the HOW2 Benchmark Study. Am J Infect Control 2014;42:602-7.

9. Larson EL, Patel SJ, Evans D, Saiman L. Feedback as a strategy to change behaviour: the devil is in the details. J Eval Clin Pract 2013;19:230-4

10. Sickbert-Bennett EE, DiBiase LM, Willis TS, Wolak ES, Weber DJ, Spears TG, et al. Reducing Healthcare-Associated Infections Via a Novel "All Hands on Deck" Approach for Hand Hygiene Compliance. Presented at: SHEA. Orlando, FL, 2015. 